\title{
Identificação das bactérias envolvidas na sepse grave de fêmeas caninas com piometra submetidas a ovário- histerectomia terapêutica
}

\author{
Identification of the microorganisms involved in severe sepsis caused by pyometra in \\ bitches undergoing ovariohysterectomy
}

\author{
Tabatha do Amaral KALENSKI ${ }^{1}$; Adriane REINOLDES ${ }^{1}$; Marcelo KITSIS ${ }^{1}$; Marcelo FAUSTINO²; \\ Mariana Semião Francisco TALIB ${ }^{2}$; Silvia Renata Gaido CORTOPASSI ${ }^{1}$ \\ ${ }^{1}$ Departamento de Cirurgia da Faculdade de Medicina Veterinária e Zootecnia da Universidade de São Paulo, São Paulo-SP, Brasil \\ ${ }^{2}$ Hospital Veterinário da Faculdade de Medicina Veterinária e Zootecnia da Universidade de São Paulo, São Paulo-SP, Brasil
}

\begin{abstract}
Resumo
A piometra é uma afecção reprodutiva comum que acomete fêmeas caninas, podendo se agravar e progredir para o quadro de sepse grave e choque séptico. A precocidade da instituição da antibioticoterapia é determinante para um melhor prognóstico. O objetivo deste estudo foi avaliar os principais microrganismos envolvidos nos casos de sepse grave em cadelas acometidas por piometra e submetidas à ovário-histerectomia terapêutica, por meio de realização de hemocultura e cultura da secreção uterina e antibiograma. Foram avaliadas 33 fêmeas caninas e o principal agente envolvido com a sepse grave secundária à piometra foi a Escherichia coli, identificada em 57,57\% dos casos. Também foram identificados Staphylococcus sp., com incidência de 9,09\%, Citrobacter koseri, Enterobacter cloacae, Enterobacter faecalis, Eduardsiella sp., Klebsiella pneumoniae e Streptococcus sp., com 3,03\% de frequência cada. Após a realização do antibiograma pelo método de difusão, os antimicrobianos que apresentaram maior eficácia contra as cepas de Escherichia coli foram a gentamicina, a enrofloxacina, a cefalexina e a associação de amoxicilina com ácido clavulânico, nesta ordem. A cultura da secreção uterina foi mais sensível que a hemocultura para identificação do agente microbiano $(\mathrm{p}<0,0001)$. A identificação bacteriana é útil para direcionar a antibioticoterapia empírica mais específica, de acordo com o perfil de sensibilidade, minimizando assim o desenvolvimento de resistência, o custo do tratamento e o risco de reações adversas aos antimicrobianos utilizados.
\end{abstract}

Palavras-chave: Fêmea canina. Sepse grave. Piometra. Cultura. Antibiograma.

\begin{abstract}
Pyometra is a common reproductive disorder that affects female dogs. It can represent a serious clinical entity and progress to severe sepsis and septic shock. The premature antibiotic therapy is crucial for a better prognosis. The aim of this study was to identify the most frequent microorganisms involved in the context of pyometra and severe sepsis in animals undergoing ovariohysterectomy, by blood and uterine secretion culture and antibiogram. The tests were conducted in 33 female dogs with pyometra. The most frequent recovered bacteria were Escherichia coli in 57.57\%. Staphylococcus sp. was also isolated, in 9.09\%. Citrobacter koseri, Enterobacter cloacae, Enterobacter faecalis, Eduardsiella $s p$., Klebsiella pneumoniae e Streptococcus $s p$. were also found with a $3.03 \%$ frequency each. After diffusion antibiotic test, the gentamicin was the most effective drug to E. coli, followed by enrofloxacin, cephalexin and the combination of amoxicillin and clavulanic acid. Uterine secretions cultures were more sensitive than blood culture to identify the bacterial $(\mathrm{p}<0.0001)$. The bacterial identification followed by an antibiogram allows to choose a better therapy in the presented disease in dogs.
\end{abstract}

Keywords: Female dog. Severe sepsis. Pyometra. Culture. Antibiogram.

\section{Introdução}

O complexo hiperplasia endometrial cística-piometra é uma das afecções mais comuns na rotina clínico-cirúrgica de pequenos animais, principalmente em fêmeas caninas. Embora possa se manifestar em qualquer idade, animais mais velhos apresentam incidência, próxima de $66 \%$ em fêmeas com idade acima de nove anos, considerando ainda que as nu-

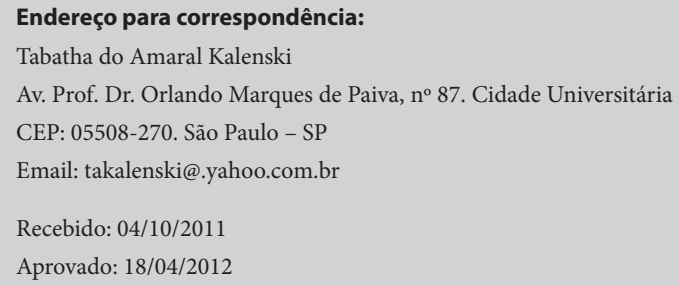


líparas apresentam maior risco de desenvolvimento desta afecção ${ }^{1}$.

A prolongada fase luteal na espécie promove o desenvolvimento de um ambiente intrauterino favorável à infecção, provoca a hiperplasia endometrial cística e o aumento da atividade secretória glandular, a qual representa uma resposta hiperplásica anormal do endométrio. Entretanto, alguns dados da literatura sugerem que a excessiva hiperplasia pode ser uma resposta à irritação causada por material estranho e/ou microbiano, resultando em uma resposta inflamatória proliferativa à infecção, o que sistematicamente pode refletir no aumento das concentrações plasmáticas de proteínas de fase aguda ${ }^{2}$. A secreção das glândulas endometriais pode levar ao acúmulo de fluido no interior uterino (hidro/mucometra) ${ }^{3}$.

Durante o período estrogênico do ciclo, quando a cérvix encontra-se relaxada e o colo uterino pérvio, pode ocorrer contaminação bacteriana ascendente na luz uterina. Isto favorece o desenvolvimento de piometra durante a fase luteal seguinte. A etiopatogenia da piometra é pouco esclarecida e as bactérias frequentemente encontradas nos casos de piometra são espécies comensais do ânus ou do trato urinário. A infecção bacteriana revela-se, pois, a principal causa da morbidade e mortalidade associadas a esta doença ${ }^{4}$.

O tratamento de eleição para a piometra é a ováriohisterectomia, associada à administração de antimicrobianos de amplo espectro e terapia de suporte (restituição hidroeletrolítica e analgésicos) ${ }^{5}$.

A piometra pode evoluir para a sepse se não diagnosticada e tratada precocemente. A sepse é definida como síndrome da resposta inflamatória sistêmica associada à infecção sanguínea presumida ou confirmada. Os sinais clínicos da síndrome da resposta inflamatória sistêmica podem ser usualmente caracterizados pela presença de pelo menos duas das quatro condições seguintes: hipo ou hipertermia, taquicardia, taquipnéia, leucopenia ou leucocitose ${ }^{6,7}$.
Quando a sepse induz a hipoperfusão tecidual ou disfunção orgânica, como lesão pulmonar aguda, distúrbios dos fatores da coagulação, trombocitopenia, alteração do estado mental, falência cardíaca, hepática ou renal, será classificada como sepse grave ${ }^{6,7}$.

Diversos autores ${ }^{8,9,10,11,12,13}$ têm demonstrado que a Escherichia coli é a bactéria mais frequentemente isolada do conteúdo uterino de fêmeas caninas com piometra. Porém, Costa et al. ${ }^{14}$ relataram, em um estudo sobre a identificação dos principais microrganismos anaeróbios envolvidos em piometras de cadelas, que o microrganismo isolado com maior frequência, colhido de secreções uterinas, foi o Corinebacterium sp.

Lara et al. ${ }^{15}$ testaram a sensibilidade antimicrobiana in vitro de cepas de E. coli isoladas de cadelas com piometra e concluíram que são resistentes aos principais antibióticos prescritos.

Assim, há divergências em relação à escolha do antimicrobiano mais indicado para os casos de piometra, de forma que a realização de um diagnóstico específico com a identificação do agente envolvido através de hemocultura e antibiograma é de importância fundamental, pois possibilita um tratamento clínico mais eficaz.

O objetivo deste estudo foi identificar os principais microrganismos envolvidos em casos de sepse grave em cadelas com piometra, submetidas à ovário-histerectomia terapêutica, por meio da realização da hemocultura, cultura da secreção uterina e antibiograma.

\section{Material e Método}

Os animais incluídos neste estudo foram provenientes do Serviço de Obstetrícia e Ginecologia do Hospital Veterinário da Faculdade de Medicina Veterinária e Zootecnia da Universidade de São Paulo.

Foram avaliados 33 animais da espécie canina, fêmeas, de raças e idades variadas, portadoras de sepse grave secundária à piometra, durante o período compreendido entre fevereiro de 2010 e janeiro de 2011. 
Foram incluídas cadelas com piometra, afecção diagnosticada a partir do histórico e dos sinais clínicos identificados por meio do exame físico e ultrassonográfico abdominal, com confirmação durante intervenção cirúrgica por meio da detecção de distensão uterina em variados graus, pelo conteúdo purulento ou sanguíneo purulento. A avaliação laboratorial, hematológica e bioquímica corroboraram o diagnóstico da gravidade da doença sistêmica.

Além de portadoras de piometra, as cadelas deveriam apresentar sepse grave, identificada pela presença de pelo menos duas variáveis da resposta inflamatória sistêmica e no mínimo uma variável de disfunção orgânica. Foram consideradas variáveis da resposta inflamatória sistêmica nesta investigação: mucosas congestas, temperatura retal menor que $37,8^{\circ} \mathrm{C}$ ou maior que $39,5^{\circ} \mathrm{C}$, taquicardia (frequência cardíaca maior que $120 \mathrm{bpm}$ ), taquipnéia (frequência respiratória maior que $30 \mathrm{mpm}$ ), pressão arterial de dióxido de carbono maior que $32 \mathrm{mmHg}$, rebaixamento do nível de consciência, hipoalbuminemia, hipoglicemia ou hiperglicemia na ausência de diabetes e alteração do número de leucócitos (acima de 18.000/ $\mathrm{mm}^{3}$, abaixo de $5.000 / \mathrm{mm}^{3}$, ou com presença de fração neutrofílica maior que 5\%). Como variáveis de disfunção orgânica, considerou-se hipotensão arterial (pressão arterial sistólica menor que $90 \mathrm{mmHg}$ ), hipoxemia (relação pressão parcial de oxigênio: fração inspirada de oxigênio abaixo de 300), oligúria aguda (débito urinário menor que $0,5 \mathrm{~mL} / \mathrm{kg} / \mathrm{h}$ ), aumento dos níveis séricos de creatinina (acima de $1,5 \mathrm{mg} / \mathrm{dL}$ ), trombocitopenia (abaixo de 150.000 plaquetas $/ \mathrm{mm}^{3}$ ) e hiperbilirrubinemia.

A ausência de crescimento bacteriano, a partir da secreção uterina, constituiu critério de exclusão.

Cada animal incluído no estudo foi submetido à punção venosa, após tricotomia e antissepsia com solução alcoólica da região da veia cefálica, safena ou jugular, para colheita de 0,5 a $4 \mathrm{~mL}$ de sangue transferido imediatamente para tubo pediátrico (BacT/
ALERT $^{\circledast}$ PF - Biomérieux - São Paulo, SP, Brasil) com meio para hemocultura.

As hemoculturas com antibiograma foram realizadas no momento da admissão dos animais e, quando positivas, foram repetidas após 10 dias da primo admissão para a avaliação da eficácia do tratamento antimicrobiano instituído.

Realizou-se também cultura da secreção uterina com antibiograma de cada animal submetido à cirurgia a fim de se comparar os resultados da hemocultura e também para adequar a escolha do antimicrobiano com maior segurança nos casos em que nenhum agente fosse identificado com auxílio de hemocultura. Assim, imediatamente após o procedimento de ovário-histerectomia, uma amostra de secreção intrauterina foi colhida e encaminhada para cultivo e antibiograma.

Os agentes microbianos identificados foram organizados e expostos de forma descritiva por meio de suas ocorrências em porcentagens, bem como a eficácia dos antimicrobianos empregados para cada agente.

Comparou-se a sensibilidade de cada um dos métodos empregados - cultura da secreção uterina e hemocultura - para identificação das bactérias por meio do teste exato de Fisher. Considerou-se como grau de significância o valor de $p<0,05$.

\section{Resultados}

Apenas um animal foi excluído do estudo, pois embora tenha apresentado resultado de hemocultura positivo com identificação de Staphylococcus chromogenes e variáveis de sepse grave, sua cultura de secreção intrauterina não identificou o agente bacteriano.

A distribuição dos casos de sepse grave secundários à piometra ao longo do ano não apresentou caráter sazonal, assim, foram detectadas hemoculturas positivas: uma em Janeiro e Outubro, duas em Maio e Agosto, três em Fevereiro, Setembro e Novembro, quatro em Março e Junho, cinco em Julho e Dezembro. 
Dezessete animais (51,51\%) apresentaram hemocultura positiva na admissão. Destes, apenas uma $(3,03 \%)$ apresentou hemocultura positiva após o tratamento com antimicrobiano. Neste caso, a bactéria foi Streptococcus $\beta$-hemolítico do grupo G e o resultado do antibiograma contribuiu na escolha de outro antimicrobiano. Este animal foi submetido a outra hemocultura após o novo tratamento, a qual foi negativa, indicando eficácia da antibioticoterapia.

O principal agente envolvido com a sepse grave secundária à piometra durante o período estudado foi a Escherichia coli, isolada em 57,57\% dos casos. Também foram isolados Staphylococcus sp., em 9,09\% e Citrobacter koseri, Enterobacter cloacae, Enterobacter faecalis, Eduardsiella sp., Klebsiella pneumoniae e Streptococcus sp., em 3,03\%. Dois animais permitiram isolar bactérias diferentes entre a hemocultura e a secreção uterina.

Os antibióticos que apresentaram melhor atividade antimicrobiana em ordem decrescente contra os isolados de Escherichia coli foram a gentamicina, a enro- floxacina, a cefalexina e a associação de amoxicilina com ácido clavulânico (Figura 1).

Os agentes identificados na hemocultura e na cultura da secreção uterina estão apresentados na tabela 1.

Para verificar a sensibilidade do cultivo bacteriano entre a hemocultura e a cultura de secreção, os resultados foram submetidos ao teste exato de Fisher, que demonstrou diferença extremamente significativa $(\mathrm{p}<0,0001)$, indicando que a cultura da secreção uterina é capaz de isolar o agente microbiano mais frequentemente do que a hemocultura.

\section{Discussão}

Durante o diestro em fêmeas caninas, a progesterona produzida pelo corpo lúteo ovariano age sobre o útero e estimula o crescimento e a atividade secretória das glândulas uterinas, promovendo assim a hiperplasia endometrial cística ${ }^{16,17}$. O endométrio torna-se cístico e espessado, proporcionando o acúmulo de fluidos e bactérias nas glândulas endometriais e luz

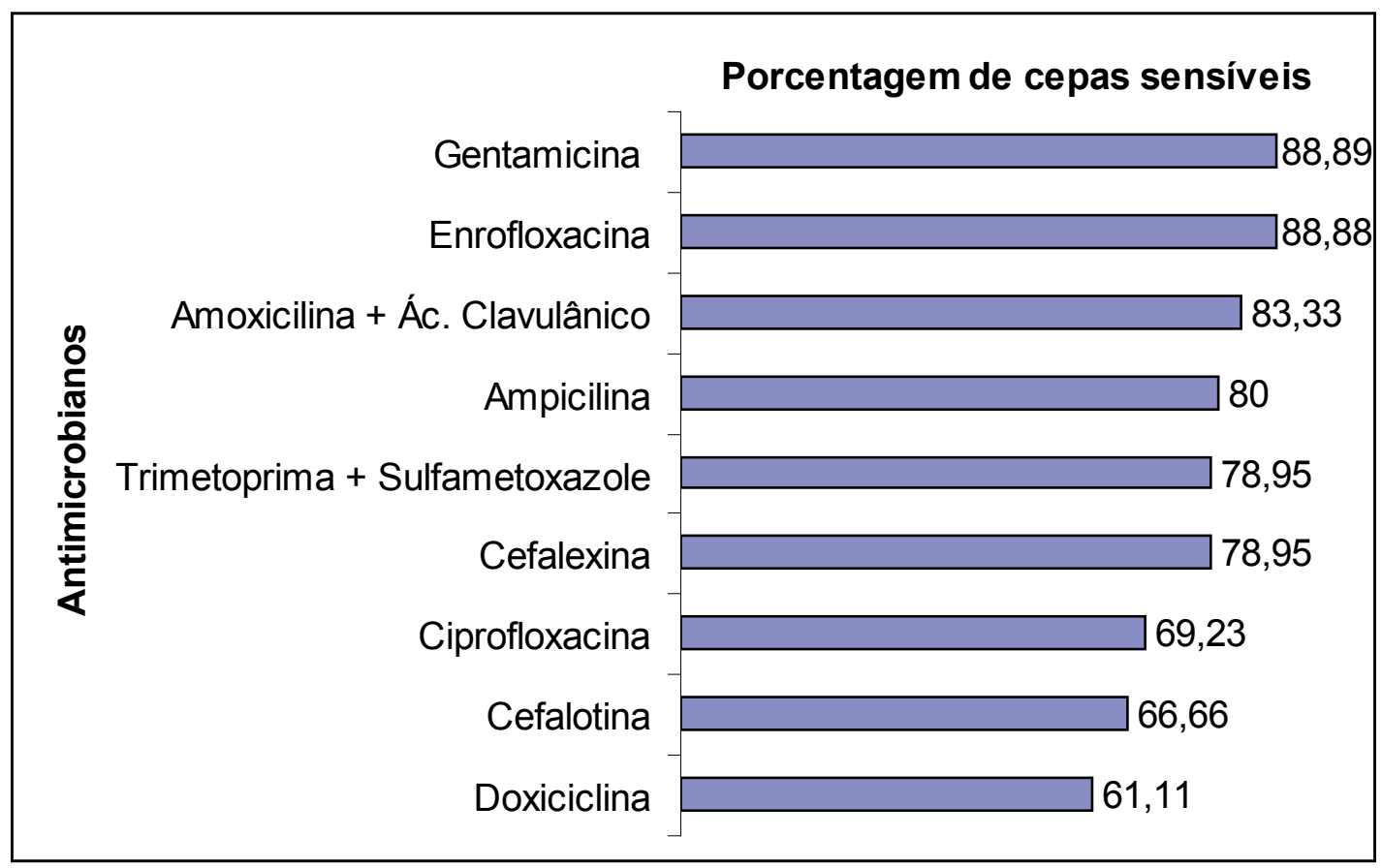

Figura 1 - Percentagem da susceptibilidade dos isolados de Escherichia coli aos principais antimicrobianos utilizados em medicina veterinária 
Tabela 1 - Agentes bacterianos identificados a partir da hemocultura e da secreção uterina

\begin{tabular}{|c|c|c|}
\hline Animal & Agente identificado à hemocultura & $\begin{array}{l}\text { Agente identificado à cultura da } \\
\text { secreção uterina }\end{array}$ \\
\hline 1 & - & A \\
\hline 2 & - & A \\
\hline 3 & - & A \\
\hline 4 & - & A \\
\hline 5 & Streptococcus $\beta$ hemolítico do grupo G & B \\
\hline 6 & Staphylococcus aureus & Staphylococcus aureus \\
\hline 7 & Citrobacter koseri & Citrobacter koseri \\
\hline 8 & Klebsiella pneumoniae & Klebsiella pneumoniae \\
\hline 9 & - & Escherichia coli \\
\hline 10 & Escherichia coli & Escherichia coli \\
\hline 11 & - & Escherichia coli \\
\hline 12 & Enterobacter cloacae & B \\
\hline 13 & Streptococcus $\beta$ hemolítico do grupo G & Streptococcus sp. \\
\hline 14 & Enterococcus faecalis & Escherichia coli \\
\hline 15 & Escherichia coli & Escherichia coli \\
\hline 16 & - & Streptococcus sp. \\
\hline 17 & Escherichia coli & Escherichia coli \\
\hline 18 & - & Escherichia coli \\
\hline 19 & - & Escherichia coli \\
\hline 20 & - & Escherichia coli \\
\hline 21 & Escherichia coli & Escherichia coli \\
\hline 22 & - & Edwardsiella sp \\
\hline 23 & - & Escherichia coli \\
\hline 24 & Escherichia coli & Escherichia coli \\
\hline 25 & Escherichia coli & Escherichia coli \\
\hline 26 & Escherichia coli & B \\
\hline 27 & - & Stafilococcus coagulase negativo \\
\hline 28 & - & B \\
\hline 29 & Escherichia coli & Escherichia coli \\
\hline 30 & Staphylococcus intermedius & Escherichia coli \\
\hline 31 & - & Escherichia coli \\
\hline 32 & - & Escherichia coli \\
\hline 33 & Escherichia coli & Escherichia coli \\
\hline
\end{tabular}

A: cultura não realizada; B: proprietário optou por eutanásia antes da realização da ovário-histerectomia terapêutica

uterina, favorecendo a colonização bacteriana por via ascendente e o aparecimento da piometra ${ }^{18,19}$. Além disso, a progesterona promove redução da resposta leucocitária e das contrações uterinas, que são mecanismos de defesa do organismo. A infecção uterina inicial pode se agravar, comprometer diversos órgãos e caracterizar o quadro de sepse grave e choque sépti$\mathrm{CO}^{20}$. Sem tratamento, a infecção é fatal ${ }^{21}$.

A sepse grave e o choque séptico são responsáveis por cerca de $2,9 \%$ das admissões hospitalares e $10 \%$ das admissões nas unidades de terapia intensiva na medicina humana ${ }^{22}$. Na medicina veterinária, apesar 
da prevalência de sepse ser desconhecida, a taxa de mortalidade parece variar entre 20 e $68 \%{ }^{23}$.

A peritonite é a causa mais frequente de sepse grave em cães e pode ser secundária à ingestão de corpo estranho, neoplasias gastrintestinais, enterotomias e ruptura uterina devido piometra ${ }^{23}$.

Para pacientes com sepse, sepse grave e choque séptico, quanto mais precoce for o início da terapia com antimicrobiano adequado, melhor será o prognóstico do paciente ${ }^{20,24}$.

Há evidências de que o ajuste da terapia de acordo com o perfil de sensibilidade aos antimicrobianos na época do recebimento do resultado das culturas melhore as chances e reduza a letalidade dos pacientes que estavam recebendo antimicrobianos inadequados, embora este benefício ocorra em menor grau quando comparado com a administração de tratamento adequado precoce ${ }^{25}$.

Embora estudos demonstrem que a susceptibilidade dos microrganismos in vitro não prediz a eficácia dos antimicrobianos in vivo ${ }^{26,27,28}$, a hemocultura pode permitir a adequação da antibioticoterapia empírica para terapia mais específica, de acordo com o perfil de sensibilidade do microrganismo, diminuindo assim o risco de aparecimento de bactérias resistentes ${ }^{29,30}$, o custo do tratamento ${ }^{31}$ e o risco de reações adversas aos antimicrobianos utilizados ${ }^{32}$.

É sabido que muitos pacientes desenvolvem sepse sem hemocultura positiva ${ }^{32}$. No presente estudo, $51,51 \%$ das cadelas com critérios para diagnóstico de sepse grave apresentaram hemocultura positiva. Em humanos, as culturas de sangue são positivas em 34\% dos pacientes com sepse, variando entre 9 e $64 \%{ }^{33}$. Quantos desses episódios são sepses não bacterêmicas ou falhas nos métodos de cultivo e identificação microbiológica, ou ainda síndrome da resposta inflamatória sistêmica não infecciosa, permanece uma incógnita ${ }^{34}$.

Das fêmeas caninas que apresentaram resultado negativo à hemocultura, quatro estavam sob antibio- ticoterapia no momento da admissão no estudo. Porém, de acordo com Schermer, Sanchez e Qualls ${ }^{35}$, o tratamento com antimicrobianos previamente à cultura sanguínea não interfere na positividade do exame. Estes autores analisaram retrospectivamente 208 pacientes humanos e não verificaram diferença significante entre o número de resultados positivos de hemocultura ao comparar os pacientes do grupo que recebiam antimicrobianoterapia profilática com aqueles que não a recebiam, ambos internados em unidade de terapia intensiva após sofrerem trauma.

Por outro lado, Darby et al. ${ }^{36}$ demonstraram que a administração de antimicrobianos concomitantemente à realização da hemocultura diminuiu a taxa de resultados positivos em um grupo heterogêneo de pacientes em unidade de terapia intensiva cirúrgica. Estes resultados conflitantes ressaltam a necessidade de novos estudos a respeito do tema que elucidem esta questão, visto que a hemocultura é um exame de custo elevado e a seleção de bactérias resistentes é um tema preocupante tanto em medicina quanto em medicina veterinária.

O presente estudo não observou maior concentração dos casos de sepse grave secundária à piometra em cadelas em algum mês específico durante um ano de colheita de dados. A cadela doméstica normalmente apresenta dois ciclos estrais por ano, mas o número de ciclos anuais pode variar de um a quatro, dependendo da raça ou de características individuais dos animais ${ }^{37}$. Por isso, as cadelas são consideradas monoéstricas não sazonais, ou seja, podem apresentar ciclos em qualquer época e os filhotes nascem em qualquer mês do ano ${ }^{38}$.

Embora Costa et al. ${ }^{14}$ tenham relatado em seu estudo sobre a identificação dos principais microrganismos anaeróbios envolvidos em piometras de cadelas, que o microrganismo isolado com maior freqüência, colhido de secreções uterinas, foi o Corinebacterium sp., esta investigação encontrou como principal agente envolvido com a sepse grave 
secundária a piometra a Escherichia coli, identificada em $57,57 \%$ dos casos, corroborando os achados de diversos autores $7,8,9,10,11,12,13$.

A incidência elevada da E.coli observada neste trabalho pode ser explicada pela afinidade que esta bactéria possui pelo epitélio do trato urinário e endométrio durante a fase de dominância da progesterona, somada à presença do precipitado bacteriano antígeno-K que favorece a colonização uterina, levando à piometra canina ${ }^{4}$.

Este estudo demonstrou índice de resistência variável de acordo com o antimicrobiano testado por parte das bactérias da espécie $E$. coli, de forma que os antimicrobianos que apresentaram melhor ação contra as cepas de Escherichia coli presentes nas cadelas estudadas foram a gentamicina, a enrofloxacina, a cefalexina e a associação de amoxicilina com ácido clavulânico, nesta ordem (Figura 1).

Hagman e $\mathrm{Greko}^{38}$ estudaram 80 amostras de $E$ coli isoladas de cadelas com piometra e verificaram taxas reduzidas de resistência aos antimicrobianos testados: $10 \%$ à ampicilina, $8 \%$ à sulfametoxazol, $5 \%$ à estreptomicina, $4 \%$ à enrofloxacina e à tetraciclina, $2 \%$ ao trimetoprim e ausência de resistência à gentamicina.

Siqueira et al. ${ }^{37}$ observaram taxa elevada de sensibilidade da E.coli aos antimicrobianos ciprofloxacina, norfloxacina e enrofloxacina; Pradhan et al. ${ }^{11}$ observaram maior sensibilidade à ciprofloxacina; Yates ${ }^{12}$ encontrou como antimicrobianos mais eficazes a gentamicina, a enrofloxacina, a amoxacilina com clavulanato e a cefalexina; Franklin e Mörner ${ }^{13}$ verificaram $100 \%$ de sensibilidade à enrofloxacina.

Diferindo dos estudos citados anteriormente, Lara et al. ${ }^{15}$ verificaram que a sensibilidade antimicrobiana in vitro de cepas de E. coli isoladas de cadelas com

\section{Referências}

1.NISKANEM, M.; THRUSFIELD, M. V. Association between age, parity, hormonal therapy and breed and pyometra in finnish dogs. Veterinary Record, v. 143, n. 18, p. 493-498, 1998. piometra foram resistentes aos principais antibióticos prescritos pelos médicos veterinários.

Esta pesquisa e a grande maioria das referências consultadas e expostas ${ }^{11,12,13,38,39}$ verificaram que a $E$. coli apresentou alta sensibilidade às fluorquinolonas. Este grupo de antimicrobianos apresenta propriedades farmacocinéticas favoráveis como amplo espectro de ação, baixa toxicidade e reduzida propensão para selecionar bactérias resistentes ${ }^{40}$. Além disso, as fluorquinolonas apresentam efeito bactericida rápido, reduzindo a contagem de $E$. coli de três a cinco logaritmos dentro de uma a duas horas ${ }^{41}$. Porém, é importante notar que, em infecções graves por agentes gram-negativos, a ação rápida de alguns antimicrobianos pode estar associada à liberação aumentada de lipopolissacarídeos da parede bacteriana (endotoxinas), levando ao agravamento do choque séptico ${ }^{42}$.

\section{Conclusões}

A partir dos resultados obtidos foi possível concluir que: a bactéria Escherichia coli é de fato o microrganismo mais frequente envolvido com a sepse grave secundária à piometra nos animais estudados; o exame de cultura da secreção uterina revelou maior sensibilidade para a detecção do agente microbiano envolvido com a piometra em relação à hemocultura; a enrofloxacina pode ser indicada para o tratamento da piometra em cadelas, pois obteve neste estudo $88,88 \%$ de eficácia in vitro contra as cepas de E. coli identificadas. Finalmente, a incidência de sepse grave secundária à piometra não apresentou distribuição sazonal ao longo do período de estudo.

\section{Agradecimentos}

À FAPESP pelo apoio financeiro (2008/56406-7).

2. CONCANNON, P. W.; VERSTEGEN, J. Some unique aspects of canine and feline female reproduction important in veterinary practice. In: WORLD SMALL ANIMAL VETERINARY 
ASSOCIATION CONGRESS, 30., 2005, Mexico City, Mexico. Proceedings... Mexico City: World Small Animal Veterinary Association, 2005.

3. NELSON, R. W.; FELDMAN, E. C. Pyometra in the bitch. In: Current therapy in theriogenology. 2. ed. Philadelphia: Saunders, 1986. p. 567-574.

4.SANDHOLM, M.; VASENIUS, H.; KIVISTO, A-K. Pathogenesis of canine pyometra. Journal of the American Veterinary Medical Association, v. 167, n. 11, p. 1006-1010, 1975

5.ENGLAND, G.C.W. Doenças do sistema reprodutivo. In: DUNN, J. K. Tratado de medicina de pequenos animais. 1. ed. São Paulo: Roca, 2001. p. 577-578.

6.DELLINGER, R. P.; LEVY, M. M.; CARLET, J. M.; BION, J.; PARKER, M.M.; JAESCHKE, R.; REINHART, K.; ANGUS, D.C.; BRUN-BUISSON, C.; BEALE, R.; CALANDRA, T.; DHAINAUT, J. F.; GERLACH, H.; HARVEY, M.; MARINI, J.J.; MARSHALL, J.; RANIERI, M.; RAMSAY, G. ; SEVRANSKY, J.; THOMPSON, B. T.; TOWNSEND, S.; VENDER, J. S.; ZIMMERMAN, J. L.; VINCENT, J. L. Surviving Sepsis Campaign: International guidelines for management of severe sepsis and septic shock: 2008. Critical Care Medicine, v. 36, n. 1, p. 296-327, 2008.

7. NGUYEN, H. B.; RIVERS, E. P.; ABRAHAMIAN, F. M.; MORAN, G. J.; ABRAHAM, E.; TRZECIAK, S.; HUANG, D. T.; OSBORN, T.; STEVENS, D.; TALAN, D. A. Severe sepsis and septic shock: Review of literature and emergency department management guidelines. Annals of Emergency Medicine, v. 48, n. 1, p. 28-54, 2006.

8. CHEN, Y. M. M.; WRIGHT, P. J.; LEE, C. S. et al. Uropathogenic virulence factors in isolates Escherichia coli from clinical cases of canine pyometra and feces of healthy bitches. Veterinary Microbiology, v. 94, n. 1, p. 57-69, 2003.

9. WERNICKI, A.; KRZYZANOWSKI, J.; PUCHALSKI, A. Characterization of Escherichia coli strains associated with canine pyometra. Polish Journal of Veterinary Science, v. 5 , n. 2, p. 51-56, 2002.

10.SILVA, L. B. G.; CASTRO JÚNIOR, I. F.; CUNHA, A. P.; MOTA, R. A.; SILVA, K. P.; PINHEIRO JR., J. W. Estudo etiológico e terapêutico da piometra em cadelas na região metropolitana de Recife-PE, Brasil. Hora Veterinária, v. 24, n. 139, p. 37-39, 2004.

11.PRADHAN, R. C.; BARIK, A. K.; RAY, S. D.; MISHRA, P. R. Antibiogram of uterine microflora in bitches with endometritis - Pyometra complex. Indian Veterinary Journal, v. 76, n. 11, p. $982-985,2000$.

12.YATES, D. G. The antimicrobial sensitivity of bacteria isolated from 30 cases of pyometra in the bitch. Irish Veterinary Journal, v. 49, n. 12 p. 709-710, 1996.

13.FRANKLIN, A.; MÖRNER, A. P. Antibiotic sensitivity of bacterial isolates from urinary tract infections and metritis in dogs. Compendium of Continuing Education Practice in Veterinary, v. 18, n. 2, p. 96, 1996.

14. COSTA, R. G.; ALVES, N. D.; NOBREGA, R. M.; CARVALHO, C. G.; QUEIROZ, I. V.; COSTA, T. H. M.; PEREIRA, R. H. M.; SOARES, H. S.; FEIJO, F. M. C. Identificação dos principais microrganismos anaeróbios envolvidos em piometras em cadelas. Acta Scientiae Veterinariae, v. 35, n. 2, p. 650-651, 2007.

15. LARA, V. M.; DONADELI, M. P.; CRUZ, F. S. F.; CARREGARO, A. B. Multirresistência antimicrobiana em cepas de Escherichia coli isoladas de cadelas com piometra. Arquivo Brasileiro de Medicina Veterinária e Zootecnia, v. 60, n. 4, p. 1032-1034, 2008.

16.WIKES, P. G.; OLSON, P. N. Moléstias do útero. In: BOJRAB,
M. J. Mecanismos da moléstia na cirurgia dos pequenos animais. 2. ed. São Paulo: Manole, 1996. p. 665-669.

17.JUTKOWITZ, L. A. Reproductive emergencies. Veterinary Clinics of North America: Small Animal Practice, v. 35, n. 2, p. 397-420, 2005.

18.FOSSUM, T. W.; HEDLUND, S. C.; HULSE, D. A. Surgery of the reproductive and genital systems. In: FOSSUM, F. W. Small animal surgery. 2. ed. Missouri: Mosby, 1997. p. 538-551.

19.ENGLAND, G. C. W.; FREEMAN, S. L.; RUSSO, M. Treatment of spontaneous pyometra in 22 bitches with a combination of cabergoline and cloprostenol. Veterinary Record, v. 160, n. 9, p. 293-296, 2007.

20.KUMAR, A.; ROBERTS, D.; WOOD, K. E.; LIGHT, B.; PARRILLO, J. E.; SHARMA, S.; SUPPES, R.; FEINSTEIN, D.; ZANOTTI, S.; TAIBERG, L.; GURKA, D.; KUMAR, A.; CHEANG, M. Duration of hypotension before initiation of effective antimicrobial therapy is the critical determinant of survival in human septic shock. Critical Care Medicine, v. 34, n. 6 , p. 1589-1596, 2006

21.FIENI, F. Clinical evaluation of the use of aglepristone, with or without cloprostenol, to treat cystic endometrial hyperplasiapyometra complex in bitches. Theriogenology, v. 66, n. 2, p. 1550-1556, 2006. Supplement.

22. RIVERS, E. P.; MCINTYRE, L.; MORRO, D. C.; RIVERS, K. K. Early and innovative interventions for severe sepsis and septic shock: taking advantage of a window of opportunity. Canadian Medical Association Journal, v. 173, n. 9, p. 1054-1065, 2005.

23. KING, L. G. Postoperative complications and prognostic indicators in dogs and cats with septic peritonitis: 23 cases (1989-1992). Journal of American Veterinary Medical Association, v. 204, n. 3, p. 407-414, 1994.

24.LEONE, M.; BOURGOIN, A.; CAMBON, S.; DUBUC, M.; ALBANĖSE, J.; MARTIN, C. Empirical antimicrobial therapy of septic shock patients: adequacy and impact on the outcome. Critical Care Medicine, v. 31, n. 6, p. 462-467, 2003.

25.GARNACHO-MONTERO, J.; GARCIA-GARMENDIA, J. L.; BARRERO-ALMODOVAR, A.; JIMENEZ-JIMENEZ, F. J.; PEREZ-PAREDES, C., ORTIZ-LEYBA, C. Impact of adequate empirical antibiotic therapy on the outcome of patients admitted to the intensive care unit with sepsis. Critical Care Medicine, v. 31, n. 12, p. 2742-2751, 2003.

26.LEROY, O.; SANTRE, C.; BEUSCART, C.; GEORGES, H.; GUERY, B.; JACQUIER, J.M.; BEAUCAIRE, G. A. fiveyear study of severe community-acquired pneumonia with emphasis on prognosis in patients admitted to an intensive care unit. Intensive Care Medicine, v. 21, n. 1, p. 21-24, 1995.

27.CRAIG, W. A. Pharmokinetic/pharmacodynamic parameters: rationale for antibacterial dosing of mice and men. Clinical Infectious Diseases, v. 26, n. 1, p. 1-10, 1998.

28. SIEGEL, R. E. The significance of serum vs tissue levels of antibiotics in the treatment of penicillin-resistant and community-acquired pneumonia: are we looking in the wrong place? Chest, v. 116, n. 2, p. 535-538, 1999.

29. TURNIDGE, J. Impact of antibiotic resistance on the treatment of sepsis. Scandinavian Journal of Infectious Diseases, v. 35, n. 9, p. 677-682, 2003.

30.BOOTHE, D. M. Interpreting culture and susceptibility data in critical care: perks and pitfalls. Journal of Veterinary Emergency and Critical Care, v. 20, n. 1, p. 110- 131, 2010.

31.COSGROVE, S. E. The relationship between antimicrobial resistance and patient outcomes: mortality, length of hospital stay, and health care costs. Clinical Infectious Diseases, v. 42, p. S82-89, 2006. Supplement, 2. 
32.NIEDERMAN, M. S.; MANDELL, L. A.; ANZUETO, A.; BASS, J. B.; BROUGHTON, W. A.; CAMPBELL, G. D.; DEAN, N.; FILE, T.; FINE, M. J.; GROSS, P. A.; MARTINEZ, F.; MARRIE, T. J.; PLOUFFE, J. F.; RAMIREZ, J.; SAROSI, G. A.; TORRES, A.; WILSON, R.; YU, V. L. Guidelines for the management of community-acquired pneumonia: diagnosis, assessment of severity antimicrobial therapy and prevention. American Journal of Respiratory and Critical Care Medicine, v. 163, n. 7, p. 1730-1754, 2001

33. BOCHUD, P. Y.; GLAUSER, M. P.; CALANDRA, T. Antibiotics in sepsis. Intensive Care Medicine, v. 27, n. 1, p. 33-48, 2001.

34.CARvalHo, P. R. A.; TROTTA, E. A. Avanços no diagnóstico e tratamento da sepse. Jornal de Pediatria, v. 79, p. S195-S204, 2003.

35.SCHERMER, C. R.; SANCHEZ, D. P.; QUALLS, C. R. Blood culturing practices in a trauma intensive care unit: does concurrent antibiotic use make a difference? Journal of Trauma, v. 52, n. 3, p. 463-468, 2002.

36.DARBY, J. M.; LINDEN, P.; PASCULLE, W.; SAUL, M. S. Utilization and diagnostic yield of blood cultures in a surgical intensive care unit. Critical Care Medicine, v. 25, n. 6, p. 989994, 1997.

37.JOHNSTON, S. D.; KUSTRITZ, M. V. R.; OLSON, P. N. S.
The Bitch: the estrous cycle In: JOHNSTON, S. D. Canine and feline theriogenology. Philadelphia: Saunders, 2001. p. 206-224.

38.SIQUEIRA, A. K.; RIBEIRO, M. G.; SALERNO, T.; TAKAHIRA, R. K.; LOPES, M. D.; PRESTES, N. C.; SILVA, A. V. Perfil de sensibilidade e multirresistência em linhagens de Escherichia coli isoladas de infecção do trato urinário, de piometra e de fezes de cães. Arquivo Brasileiro de Medicina Veterinária e Zootecnia, v. 60, n. 5, p. 1263-1266, 2008.

39.HAGMAN, R.; GREKO, C. Antimicrobial resistance in Escherichia coli isolated from bitches with pyometra and from urine samples from other dogs. Veterinary Record, v. 157, n. 7, p. 193-197, 2005

40.MCKELLAR, Q. A. Clinical relevance of the pharmacologic properties of fluorquinolones. Compendium of Continuing Education Practice in Veterinary, v. 18, n. 2, p. 14-20, 1996.

41.DIVER, J. M.; WISE, R. Morphological and biochemical changes in Escherichia coli after exposure to ciprofloxacin. Journal of Antimicrobials and Chemotherapy, v. 18, p. 3141, 1986. Supplement D.

42.COHEN, J.; MCCONNELL, J. S. Antibiotic-induced endotoxin release. Lancet, v. 326, n. 8463, p. 1069-1070, 1985. 